\title{
Stenting left main disease: all roads lead to Rome
}

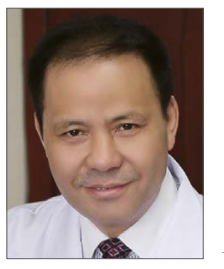

Shao-Liang Chen*, MD, $\mathrm{PhD}$

Nanjing First Hospital, Nanjing Medical University, Nanjing, China

The incidence of left main (LM) disease is reported by angiography to be $\sim 10 \%{ }^{1}$. At the root of the left coronary artery, the LM segment is divided into segments: ostial (proximal $3-5 \mathrm{~mm}$ ), body (mid-segment, $5 \mathrm{~mm}$ in length), and distal (distal $5 \mathrm{~mm}$ ). When the length of the LM is $<10 \mathrm{~mm}$, from the standpoint of percutaneous coronary intervention (PCI), most interventional cardiologists prefer to cover the whole LM segment using a drug-eluting stent (DES) unless there is a clear proximal landing zone. There are also isolated distal LM lesions, where $>80 \%$ of the disease ${ }^{2}$ is seen to extend to the left anterior descending artery (LAD). Of the total number of LM lesions, $\sim 85 \%$ involve both the LAD and left circumflex (LCX), forming distal LM bifurcation lesions ${ }^{3}$.

Criteria for LM treatment ${ }^{2,4}$ are: 1) LM diameter stenosis $\geq 70 \%$ measured by angiography, 2) minimal luminal area (MLA) $\leq 6.0 \mathrm{~mm}^{2}$ measured by intravascular ultrasound (IVUS) or optical coherence tomography (OCT), or 3) fractional flow reserve (FFR) $\leq 0.80$. While the impact of LM disease location on clinical outcome after coronary artery bypass graft (CABG) can largely be ignored, the question of how to stent distal LM lesions is a key issue. Of a total of 2,775 patients with isolated ostial/midshaft lesions in unprotected LM disease enrolled in the DELTA multinational registry ${ }^{5}$, at a median follow-up period of 1,293 days, there were no significant differences in the propensity score-adjusted analyses for the composite endpoint of all-cause death, myocardial infarction (MI), and cerebrovascular accident between the PCI and CABG groups, with the exception of a higher rate of target vessel revascularisation (TVR) in the PCI arm. In a recent meta-analysis $^{6}$ including 29 studies extracted with 21,832 patients $(10,424$ in PCI vs 11,408 in CABG), for the entire cohort of LM disease, the pooled analysis demonstrated remarkable differences in $\geq 1$ year follow-up of major adverse cardiac and cerebrovascular events (MACCE), TVR, and MI, favouring CABG over PCI. Obviously, it is presumed that LM distal lesions are mainly correlated with increased clinical events after PCI. This finding is in line with two more recent large clinical trials ${ }^{7,8}$ with $>3$-year follow-up. In the EXCEL trial 7 , in which 1,905 patients with unprotected left main coronary artery disease (ULMCAD) and low or intermediate SYNTAX scores were randomised to PCI with second-generation everolimus-eluting stents versus $\mathrm{CABG}, \sim 80 \%$ of patients had disease of the distal LM bifurcation, most commonly treated with 
a provisional stenting (PS) approach. Although PCI provided comparable three-year composite rates of death, myocardial infarction (MI) or stroke compared to $\mathrm{CABG}$, repeat revascularisation rates after 30 days were higher with PCI. In the NOBLE trial ${ }^{8}, \sim 80 \%$ of patients also had distal LM involvement, again most often treated with a PS strategy. In NOBLE, PCI with an earlier-generation DES resulted in a higher composite rate of death, MI, stroke or TVR at five years than CABG.

The PS approach to true bifurcation lesions consists of placing a DES in the main branch and performing balloon angioplasty of the side branch (SB), with stenting of the SB (usually with a $\mathrm{T}$ technique) reserved for a suboptimal balloon result. Therefore, whether alternative approaches to distal LM bifurcation might afford superior results is unknown. In this issue of AsiaIntervention, Dejan Milasinovic and Goran Stankovic ${ }^{9}$ have systematically analysed the similarities and differences between PS and upfront two-stent approaches for LM bifurcation.

\section{Article, see page 85}

In this paper there are no further "disclosures" concerning the comparison of PS versus two-stent treatments. However, the following issues remain problematic.

\section{Is the complexity of LM bifurcations influencing clinical outcome after $\mathrm{PCI}$ ?}

The 2018 ESC/EACTS guidelines on myocardial revascularisation ${ }^{10}$ recommended the use of a systematic two-stent approach for true coronary bifurcation lesions if there is a large SB $(\geq 2.75 \mathrm{~mm}$ in diameter) with a long ostial SB lesion $(>5 \mathrm{~mm})$, anticipated difficulty in accessing an important SB after MV stenting, or true distal LM bifurcations. However, there is a lack of widespread agreement concerning how to define complex bifurcation lesions. In 2014, the DEFINITION criteria of complex bifurcation lesions ${ }^{11}$ were developed from a large bifurcation cohort $(n=1,550$ patients) and subsequently validated in a 3,660-patient study. Significant reductions in mortality and in-hospital adverse events were observed in patients with complex bifurcation lesions defined according to these criteria treated with routine two-stent techniques. The subsequent DEFINITION II trial ${ }^{12}$ showed that a planned two-stent strategy significantly reduced the incidence of one-year target lesion failure (TLF) compared with provisional stenting, driven by fewer target vessel MI (TVMI) and clinically driven target lesion revascularisation (TLR). In that study, $\sim 80 \%$ of two-stent techniques were double kissing (DK) crush, leading to the conclusion that DK crush is the winner. In fact, DKCRUSH $\mathrm{V}^{13}$, the second randomised trial comparing DK crush with PS for LM distal bifurcation lesions, reported a significant reduction of 1- to 3-year TLF in patients with complex bifurcations stratified by the DEFINITION criteria, supported by a recently published retrospective study ${ }^{14}$. Altogether, the DEFINITION criteria consisting of angiographic parameters provide the reliability of separating simple from complex bifurcation lesions and a prediction value for the occurrence of clinical events after LM bifurcation PCI.

\section{What is the intrinsic difference between culotte and DK double crush?}

Culotte stenting was and continues to be the main technique in a systematic two-stent approach for true coronary bifurcation lesions. In the DKCRUSH III study ${ }^{15}$, patients in the culotte group had a significantly higher rate of one-year major adverse cardiac events (MACE, including cardiac death, MI, and TVR), mainly driven by increased TVR, compared with the DK crush. Interestingly, the one-year MACE rate after culotte stenting for LM bifurcation lesions was similar in the DKCRUSH III $(16.3 \%)$ and $\operatorname{EBC}$ MAIN (17.7\%, all-death in this trial) ${ }^{15,16}$ trials. Furthermore, at three-year follow-up in the DKCRUSH III study ${ }^{17}$, the difference in MACE between the culotte and DK crush groups had widened, accompanied by a significantly higher rate of stent thrombosis in the culotte arm. As a result, the culotte stenting approach should be moved from the list of upfront two-stent techniques for treatment of LM bifurcation lesions.

\section{Why is there a higher rate of periprocedural MI (PMI) after a PS approach?}

Post-stenting MI consists of PMI and spontaneous MI. The rate of spontaneous MI is comparable between PS and a two-stent approach $^{12-17}$; however, the rate of PMI was significantly higher in the PS arm of the DKCRUSH V ${ }^{13}$ and DEFINITION II ${ }^{12}$ trials. In a total of 405 patients with 405 bifurcation lesions who underwent preprocedural OCT imaging of both the main vessel (MV) and the $\mathrm{SB}^{18}$, vulnerable plaques were predominantly localised in the MV and were more frequently in the long $\mathrm{SB}(\geq 10 \mathrm{~mm})$ lesion group (42.7\%) than in the short SB lesion group $(24.2 \%$, $\mathrm{p}<0.001)$. At one-year follow-up after provisional stenting, there were $31(7.7 \%)$ TVMIs, with $21(11.8 \%)$ in the long SB lesion group and $10(4.4 \%)$ in the short SB lesion group ( $p=0.009)$. Multivariate regression analysis showed that long SB lesion length, vulnerable plaques in the polygon of confluence, and true coronary bifurcation lesions were the three independent factors of TVMI. Obviously, SB lesion length plays an important role in stenting selection and predicting worse events (Table 1), consistent with a recent meta-analysis ${ }^{19}$.

\section{What is the correlation between PMI and mortality after bifurcation stenting?}

PMI refers to myonecrosis following PCI using DES. Its rate varies from $1.1 \%$ to $55.9 \%$ depending on the types and cut-off values of biomarkers and additional electrocardiogram (ECG) criteria or clinical symptoms. The pathophysiology of PMI is multifactorial and includes distal embolisation of thrombus or plaques, dissection, spasm, and occlusion of small SBs. In 1,971 patients with true coronary bifurcations who underwent DES implantation in the DEFINITION trial ${ }^{11}$, we reported that one-year mortality was significantly higher in the PMI group (defined as creatinine kinase [CK]-myocardial band [CK-MB] $>3$ times above the upper normal limit [UNL], 6.4\%) than in the non-PMI group (1.7\%). Among 1,300 patients with both CK and CK-MB 
Table 1. Correlation of side branch lesion length with worse events at one-year after provisional stenting.

\begin{tabular}{|c|c|c|c|c|c|}
\hline 1-year follow-up & Cardiac death & TVMI & TLR & TLF & ST \\
\hline SB lesion length $<5 \mathrm{~mm}$ & $0.8 \%$ & 0 & $2.1 \%$ & $2.5 \%$ & 0 \\
\hline SB lesion length $=5 \mathrm{~mm}$ but $<10 \mathrm{~mm}$ & $1.3 \%$ & $3.3 \%$ & $4.5 \%$ & $6.6 \%$ & 0 \\
\hline SB lesion length $\geq 10 \mathrm{~mm}$ & $2.2 \%$ & $6.1 \%$ & $8.4 \%$ & $13.4 \%$ & $2.7 \%$ \\
\hline
\end{tabular}

measurements pre- and post-stenting were evaluated from four DKCRUSH studies ${ }^{20}$, Sheiban and co-workers reported that 56 (4.3\%) patients had PMI. According to SYNTAX ${ }^{21}$, the Fourth Universal Definition of Myocardial Infarction $\left(4^{\text {th }} \text { UDMI }\right)^{22}$ or ISCHEMIA $^{23}, \mathrm{SCAI}^{24}$, and EXCEL ${ }^{7}$ trial definitions (Table 2), PMI occurred in 21 (1.6\%), 56 (4.3\%), 29 (2.2\%), and $32(2.5 \%)$ patients, respectively. All definitions were significantly correlated with unadjusted mortality at the end of follow-up but not at 30 days or one year after stenting. PMI using SYNTAX, SCAI, and EXCEL definitions rather than the 4th UDMI definition was strongly associated with adjusted all-cause death. By adjusted analysis, PMI according to the 4th UDMI, SCAI, and EXCEL definitions (but not the SYNTAX definition) was positively correlated with cardiac death at a median of 5.58 years of follow-up. $\mathrm{CK}-\mathrm{MB} \geq 5 \times \mathrm{UNL}$ strongly enhanced the correlation of CK-MB values with mortality (Table 3 ). Accordingly, intravascular imaging guidance of bifurcation stenting is critical for improving clinical outcomes.

\section{Conclusion}

Stenting LM bifurcation lesions is technically demanding. Careful assessments according to angiography, intravascular images, and/ or fractional flow reserve (FFR) are key points of device and approach selection (Figure 1). The quality of stenting procedures determines the short- and long-term clinical outcomes. DK crush is associated with less frequent worse clinical events, particularly for complex bifurcation lesions defined according to the DEFINITION criteria.

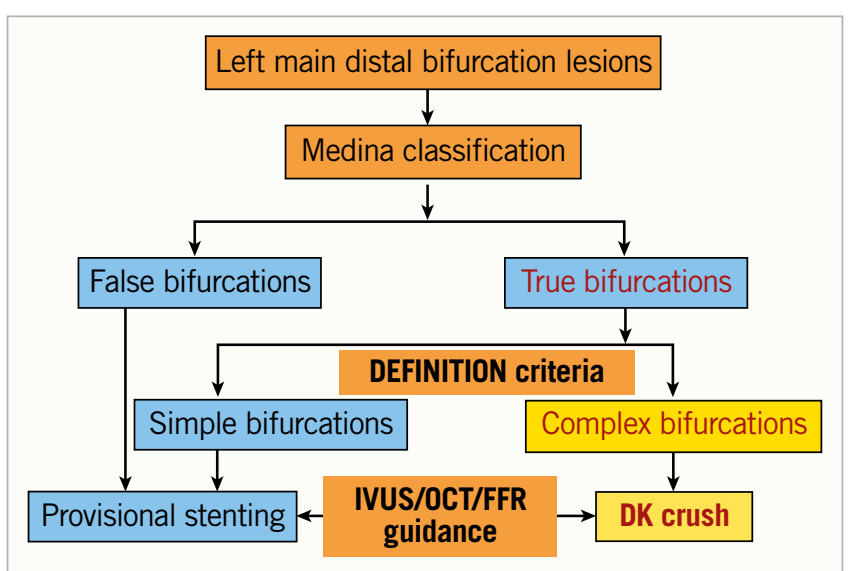

Figure 1. Algorithm of stenting left main distal bifurcation lesions.
Table 2. Components of definitions for periprocedural myocardial infarction.

\begin{tabular}{|c|c|}
\hline & Component of definitions \\
\hline \multirow{3}{*}{$\begin{array}{l}\text { SYNTAX } \\
\text { definition }^{21}\end{array}$} & New $Q$-waves in $\geq 2$ leads \\
\hline & peak CK-MB/peak total CK >10\% \\
\hline & CK-MB >5×UNL \\
\hline \multirow{6}{*}{$\begin{array}{l}\text { 4th UDMI } \\
\text { definition } 22\end{array}$} & CK-MB >5×99\% percentile UNL \\
\hline & new ischaemic ECG changes \\
\hline & new Q-waves \\
\hline & flow-limiting complications \\
\hline & new loss of viable myocardium \\
\hline & new wall motion abnormally \\
\hline \multirow{7}{*}{$\begin{array}{l}\text { ISCHEMIA } \\
\text { definition }{ }^{23}\end{array}$} & CK-MB $>5 \times U N L$ \\
\hline & ST-segment elevation or depression \\
\hline & new Q-waves \\
\hline & persistent LBBB \\
\hline & new TIMI flow $0 / 1$ in major vessel or SB \\
\hline & NHLBI $\geq$ type $\mathrm{C}$ dissection \\
\hline & CK-MB >10xUNL \\
\hline \multirow[t]{4}{*}{ SCAI definition ${ }^{24}$} & CK-MB $\geq 5 \times U N L$ \\
\hline & new Q-waves \\
\hline & persistent LBBB \\
\hline & CK-MB >10xUNL \\
\hline \multirow[t]{7}{*}{ EXCEL definition ${ }^{7}$} & CK-MB $>5 \times U N L$ \\
\hline & new Q-waves \\
\hline & persistent LBBB \\
\hline & occlusion, new thrombosis or $\mathrm{TIMI}<3$ \\
\hline & new loss of viable myocardium \\
\hline & new regional wall motion abnormally \\
\hline & CK-MB >10xUNL \\
\hline \multicolumn{2}{|c|}{$\begin{array}{l}\text { CK-MB: creatine kinase myocardial band; LBB: left bundle branch; } \\
\text { LBBB: left bundle branch block; NHLBI: National Heart, Lung, and } \\
\text { Blood Institute TIMI: Thrombolysis In Myocardial Infarction; UNL: upper } \\
\text { normal limit }\end{array}$} \\
\hline
\end{tabular}

\section{Conflict of interest statement}

The author has no conflicts of interest to declare.

\section{References}

1. De Caterina AR, Cuculi F, Banning AP. Incidence, predictors and management of left main coronary artery stent restenosis: a comprehensive review in the era of drug-eluting stents. EuroIntervention. 2013;8:1326-34. 
Table 3. Association of CK-MB values with all-cause or cardiac death at the end of follow-up.

\begin{tabular}{|l|c|c|c|c|c|c|}
\hline \multirow{2}{*}{ CK-MB increases (xULN) } & \multicolumn{3}{c|}{ All-cause death } & \multicolumn{3}{c|}{ Cardiac death } \\
\cline { 2 - 7 } & Event, N (\%) & HR & $95 \%$ CI & Event, N (\%) & HR & 95\% CI \\
\hline CK-MB $<1 \times U N L$ & $46 / 577(8.0)$ & - & - & $25 / 577(4.3)$ & - \\
\hline $1 \times U N L \leq C K-M B ~<3 \times U N L$ & $61 / 598(10.2)$ & 0.63 & $0.36-1.10$ & $38 / 598(6.4)$ & 0.59 & $0.30-1.13$ \\
\hline $3 \times U N L \leq C K-M B<5 \times U N L$ & $8 / 68(11.8)$ & 1.08 & $0.49-2.35$ & $4 / 68(5.9)$ & 0.81 & $0.28-2.32$ \\
\hline CK-MB $\geq 5 \times U N L$ & $11 / 57(19.3)$ & 2.07 & $1.02-4.18$ & $9 / 57(15.8)$ & 2.79 & $1.28-6.06$ \\
\hline Cl: confidence interval: CK-MB: creatine kinase myocardial band; HR: hazard ratio; UNL: upper normal limit & \\
\hline
\end{tabular}

2. de la Torre Hernandez JM, Hernández Hernandez F, Alfonso F, Rumoroso JR, Lopez-Palop R, Sadaba M, Carrillo P, Rondan J, Lozano I, Ruiz Nodar JM, Baz JA, Fernandez Nofrerias E, Pajin F, Garcia Camarero T, Gutierrez H; LITRO Study Group (Spanish Working Group on Interventional Cardiology). Prospective application of pre-defined intravascular ultrasound criteria for assessment of intermediate left main coronary artery lesions from the multicenter LITRO study. J Am Coll Cardiol. 2011;58:351-8.

3. Rab T, Sheiban I, Louvard Y, Sawaja FJ, Zhang JJ, Chen SL. Current Interventions for the Left Main Bifurcation. JACC Cardiovasc Interv. 2017;10:849-65.

4. Stone GW, Sabik JF, Serruys PW, Simonton CA, Généreux P, Puskas J, Kandzari DE, Morice MC, Lembo N, Brown WM 3rd, Taggart DP, Banning A, Merkely B, Horkay F, Boonstra PW, van Boven AJ, Ungi I, Bogáts G, Mansour S, Noiseux N, Sabaté M, Pomar J, Hickey M, Gershlick A, Buszman P, Bochenek A, Schampaert E, Pagé P, Dressler O, Kosmidou I, Mehran R, Pocock SJ, Kappetein AP; EXCEL Trial Investigators. Everolimuseluting stents or bypass surgery for left main coronary artery disease. $N$ Engl J Med. 2016;375:2223-35.

5. Naganuma T, Chieffo A, Meliga E, Capodanno D, Park SJ, Onuma Y, Valgimigli M, Jegere S, Makkar RR, Palacios IF, Costopoulos C, Kim YH, Buszman PP, Chakravarty T, Sheiban I, Mehran R, Naber C, Margey R, Agnihotri A, Marra S, Capranzano P, Leon MB, Moses JW, Fajadet J, Lefevre T, Morice MC, Erglis A, Tamburino C, Alfieri O, Serruys PW, Colombo A. Long-term clinical outcomes after percutaneous coronary intervention versus coronary artery bypass grafting for ostial/midshaft lesions in unprotected left main coronary artery from the DELTA registry: a multicenter registry evaluating percutaneous coronary intervention versus coronary artery bypass grafting for left main treatment. JACC Cardiovasc Interv. 2014;7:354-61.

6. Ali WE, Vaidya SR, Ejeh SU, Okoroafor KU. Meta-analysis study comparing percutaneous coronary intervention/drug eluting stent versus coronary artery bypass surgery of unprotected left main coronary artery disease: Clinical outcomes during short-term versus longterm (> 1 year) follow-up. Medicine (Baltimore). 2018;97:e9909.

7. Belley-Côté EP, Lamy AR, Whitlock RP. Everolimus-Eluting Stents or Bypass Surgery for Left Main Coronary Disease. N Engl JMed. 2017;376:1087-8.

8. Mäkikallio T, Holm NR, Lindsay M, Spence MS, Erglis A, Menown IB, Trovik T, Eskola M, Romppanen H, Kellerth T,
Ravkilde J, Jensen LO, Kalinauskas G, Linder RB, Pentikainen M, Hervold A, Banning A, Zaman A, Cotton J, Eriksen E, Margus S, Sørensen HT, Nielsen PH, Niemelä M, Kervinen K, Lassen JF, Maeng M, Oldroyd K, Berg G, Walsh SJ, Hanratty CG, Kumsars I, Stradins P, Steigen TK, Fröbert O, Graham AN, Endresen PC, Corbascio M, Kajander O, Trivedi U, Hartikainen J, Anttila V, Hildick-Smith D, Thuesen L, Christiansen EH; NOBLE study investigators. Percutaneous coronary angioplasty versus coronary artery bypass grafting in treatment of unprotected left main stenosis (NOBLE): a prospective, randomised, open-label, non-inferiority trial. Lancet. 2016;388:2743-52.

9. Milasinovic D, Stankovic G. Towards a common pathway for the treatment of left main disease: contemporary evidence and future directions. AsiaIntervention. 2021;17:85-95.

10. Neumann FJ, Sousa-Uva M, Ahlsson A, Alfonso F, Banning AP, Benedetto U, Byrne RA, Collet JP, Falk V, Head SJ, Jüni P, Kastrati A, Koller A, Kristensen SD, Niebauer J, Richter DJ, Seferovic PM, Sibbing D, Stefanini GG, Windecker S, Yadav R, Zembala MO; ESC Scientific Document Group. 2018 ESC/EACTS guidelines on myocardial revascularization. Eur Heart J. 2019;40:87-165.

11. Chen SL, Sheiban I, Xu B, Jepson N, Paiboon C, Zhang JJ, Ye F, Sansoto T, Kwan TW, Lee M, Han YL, Lv SZ, Wen SY, Zhang Q, Wang HC, Jiang TM, Wang Y, Chen LL, Tian NL, Cao F, Qiu CG, Zhang YJ, Leon MB. Impact of the complexity of bifurcation lesions treated with drug-eluting stents: the DEFINITION study (Definitions and impact of complEx biFurcation lesIons on clinical outcomes after percutaNeous coronary IntervenTIOn using drugeluting steNts). JACC Cardiovasc Interv. 2014;7:1266-76.

12. Zhang JJ, Ye F, Xu K, Kan J, Tao L, Santoso T, Munawar M, Tresukosol D, Li L, Sheiban I, Li F, Tian NL, Rodríguez AE, Paiboon C, Lavarra F, Lu S, Vichairuangthum K, Zeng H, Chen L, Zhang R, Ding S, Gao F, Jin Z, Hong L, Ma L, Wen S, Wu X, Yang S, Yin WH, Zhang J, Wang Y, Zheng Y, Zhou L, Zhou L, Zhu Y, Xu T, Wang X, Qu H, Tian Y, Lin S, Liu L, Lu Q, Li Q, Li B, Jiang Q, Han L, Gan G, Yu M, Pan D, Shang Z, Zhao Y, Liu Z, Yuan Y, Chen C, Stone GW, Han Y, Chen SL. Multicentre, randomized comparison of two-stent and provisional stenting techniques in patients with complex coronary bifurcation lesions: the DEFINITION II trial. Eur Heart J. 2020;41:2523-36.

13. Chen SL, Zhang JJ, Han Y, Kan J, Chen L, Qiu C, Jiang T, Tao L, Zeng H, Li L, Xia Y, Gao C, Santoso T, Paiboon C, Wang Y, Kwan TW, Ye F, Tian N, Liu Z, Lin S, Lu C, Wen S, Hong L, 
Zhang Q, Sheiban I, Xu Y, Wang L, Rab TS, Li Z, Cheng G, Cui L, Leon MB, Stone GW. Double Kissing Crush Versus Provisional Stenting for Left Main Distal Bifurcation Lesions: DKCRUSH-V Randomized Trial. J Am Coll Cardiol. 2017;70:2605-17.

14. Wang J, Guan C, Chen J, Dou K, Tang Y, Yang W, Shi Y, Hu F, Song L, Yuan J, Cui J, Zhang M, Hou S, Wu Y, Yang Y, Qiao S, $\mathrm{Xu}$ B. Validation of bifurcation DEFINITION criteria and comparison of stenting strategies in true left main bifurcation lesions. Sci Rep. 2020;10:10461.

15. Chen SL, Xu B, Han YL, Sheiban I, Zhang JJ, Ye F, Kwan TW, Paiboon C, Zhou YJ, Lv SZ, Dangas GD, Xu YW, Wen SY, Hong L, Zhang RY, Wang HC, Jiang TM, Wang Y, Chen F, Yuan ZY, Li WM, Leon MB. Comparison of double kissing crush versus Culotte stenting for unprotected distal left main bifurcation lesions: results from a multicenter, randomized, prospective DKCRUSH-III study. J Am Coll Cardiol. 2013;61:1482-8.

16. Hildick-Smith D, Egred M, Banning A, Brunel P, Ferenc M, Hovasse T, Wlodarczak A, Pan M, Schmitz T, Silvestri M, Erglis A, Kretov E, Lassen JF, Chieffo A, Lefèvre T, Burzotta F, Cockburn J, Darremont O, Stankovic G, Morice MC, Louvard Y. The European bifurcation club Left Main Coronary Stent study: a randomized comparison of stepwise provisional vs. systematic dual stenting strategies (EBC MAIN). Eur Heart J. 2021:ehab283.

17. Chen SL, Xu B, Han YL, Sheiban I, Zhang JJ, Ye F, Kwan TW, Paiboon C, Zhou YJ, Lv SZ, Dangas GD, Xu YW, Wen SY, Hong L, Zhang RY, Wang HC, Jiang TM, Wang Y, Sansoto T, Chen F, Yuan ZY, Li WM, Leon MB. Clinical Outcome After DK Crush Versus Culotte Stenting of Distal Left Main Bifurcation Lesions: The 3-Year Follow-Up Results of the DKCRUSH-III Study. JACC Cardiovasc Interv. 2015;8:1335-42.

18. Li X, Kan J, She L, Shrestha R, Pan T, You W, Wu Z, Ge Z, Zhang JJ, Gogas BD, Ye F, Chen SL. Optical coherence tomography predictors of target vessel myocardial infarction after provisional stenting in patients with coronary bifurcation disease. Catheter Cardiovasc Interv. 2021;97:1331-40.

19. Di Gioia G, Sonck J, Ferenc M, Chen SL, Colaiori I, Gallinoro E, Mizukami T, Kodeboina M, Nagumo S, Franco D, Bartunek J, Vanderheyden M, Wyffels E, De Bruyne B, Lassen JF, Bennett J, Vassilev D, Serruys PW, Stankovic G, Louvard Y, Barbato E, Collet C. Clinical Outcomes Following Coronary Bifurcation PCI Techniques:
A Systematic Review and Network Meta-Analysis Comprising 5,711 Patients. JACC Cardiovasc Interv. 2020;13:1432-44.

20. Sheiban I, Ge Z, Kan J, Nie S, Zhang JJ, Santoso T, Munawar M, Ye F, Han Y, Chen SL; for DKCRUSH serial trials. Association of peri-procedural myocardial infarction with mortality after stenting true coronary bifurcation lesions: A pooled individual participant data analysis from four randomized controlled trials. Catheter Cardiovasc Interv. 2021 Sep 7. [Epub ahead of print].

21. Hara H, Serruys PW, Takahashi K, Kawashima H, Ono M, Gao C, Wang R, Mohr FW, Holmes DR, Davierwala PM, Head SJ, Thuijs DJFM, Milojevic M, Kappetein AP, Garg S, Onuma Y, Mack MJ; SYNTAX Extended Survival Investigators. Impact of Peri-Procedural Myocardial Infarction on Outcomes After Revascularization. J Am Coll Cardiol. 2020;76:1622-39.

22. Thygesen K, Alpert JS, Jaffe AS, Chaitman BR, Bax JJ, Morrow DA, White HD; Executive Group on behalf of the Joint European Society of Cardiology (ESC)/American College of Cardiology (ACC)/American Heart Association (AHA)/World Heart Federation (WHF) Task Force for the Universal Definition of Myocardial Infarction. Fourth Universal Definition of Myocardial Infarction (2018). J Am Coll Cardiol. 2018;72:2231-64.

23. Maron DJ, Hochman JS, Reynolds HR, Bangalore S, O’Brien SM, Boden WE, Chaitman BR, Senior R, López-Sendón J, Alexander KP, Lopes RD, Shaw LJ, Berger JS, Newman JD, Sidhu MS, Goodman SG, Ruzyllo W, Gosselin G, Maggioni AP, White HD, Bhargava B, Min JK, Mancini GBJ, Berman DS, Picard MH, Kwong RY, Ali ZA, Mark DB, Spertus JA, Krishnan MN, Elghamaz A, Moorthy N, Hueb WA, Demkow M, Mavromatis K, Bockeria O, Peteiro J, Miller TD, Szwed H, Doerr R, Keltai M, Selvanayagam JB, Steg PG, Held C, Kohsaka S, Mavromichalis S, Kirby R, Jeffries NO, Harrell FE Jr, Rockhold FW, Broderick S, Ferguson TB Jr, Williams DO, Harrington RA, Stone GW, Rosenberg Y; ISCHEMIA Research Group. Initial Invasive or Conservative Strategy for Stable Coronary Disease. N Engl J Med. 2020;382:1395-407.

24. Moussa ID, Klein LW, Shah B, Mehran R, Mack MJ, Brilakis ES, Reilly JP, Zoghbi G, Holper E, Stone GW. Consideration of a new definition of clinically relevant myocardial infarction after coronary revascularization: an expert consensus document from the Society for Cardiovascular Angiography and Interventions (SCAI). J Am Coll Cardiol. 2013;62:1563-70. 